\title{
$O$ recado do morro: uma teoria da linguagem, uma alegoria do Brasil
}

Regina Zilberman I PUCRS

Resumo: "O Recado do Morro", narrativa que faz parte de Corpo de Baile (1956), de Guimarães Rosa, funda-se no motivo da viagem para privilegiar a escrita da natureza e a alegoria do Brasil.

Palavras-chave: escrita; alegoria; viagem; profecia; linguagem.

\begin{abstract}
De qualidade também que, os que sabem ler e escrever, a modo que mesmo o trivial da idéia deles deve de ser muito diferente.

Guimarães Rosa, O Recado do Morro
\end{abstract}

Motivo recorrente na obra de Guimarães Rosa, a viagem estrutura boa parte das histórias de Sagarana, de que são exemplo evidentes os contos "O Burrinho Pedrês" e "Duelo". "A Volta do Marido Pródigo", "Minha Gente" e "Conversa de Bois" igualmente supõem o deslocamento no espaço dos protagonistas, ainda que a viagem não constitua o tema central da intriga.

As duas narrativas que abrem Corpo de baile, "Campo Geral" e "Uma Estória de Amor", não contradizem o padrão de Sagarana no que se refere ao motivo da viagem: Miguilim, protagonista do primeiro relato, afastase de sua terra natal ao final da intriga; Manuelzão, herói do segundo, é 
homem sem paradeiro fixo. "Dão-lalalão", por sua vez, narra o retorno do protagonista à casa, onde espera encontrar, à sua espera, a esposa Doralda. Contudo, é "O Recado do Morro" o texto em que a viagem ocupa um papel central no desenvolvimento do enredo. Esse apresenta, pelo menos, duas modalidades de deslocamento no espaço: a viagem da comitiva, de um lado; a do recado, de outro.

A primeira é uma viagem exploratória, comandada pelo naturalista estrangeiro Alquist (grafado igualmente Alquiste e Olquist), pelo religioso Frei Sinfrão, e por um fazendeiro da região, seu Jujuca. Acompanham o grupo Pedro Orósio, o Pê-Boi, na condição de guia, e Ivo Crônico, que fecha a comitiva, "tangendo os burros" (ROSA, 1995, p. 618). 'A segunda viagem diz respeito à travessia do recado sugerido pelo título, cujo conteúdo assombra: avisa-se que alguém vai morrer, "à traição" (p. 630). A importância do recado não reside propriamente na revelação de que uma morte pode ocorrer, mas nas características do ato - a traição.

\section{Uma teoria da linguagem}

Vale a pena acompanhar o trajeto do recado. O emissor é singular: trata-se do Morro da Garça, monte situado no centro geodésico do estado de Minas Gerais, que proclama os possíveis acontecimentos futuros. A singularidade se amplia, quando se verificam as qualidades do Morro: a primeira - a imutabilidade - é própria a esse tipo de acidente geográfico; a segunda - a onipresença - é aceitável, num território em que constitui o elemento mais alto, visível, pois, desde diferentes ângulos, ainda que, no lugar em que a ação se passa, predominem as serras; mas a terceira - a capacidade de se comunicar - surpreende não apenas o leitor, mas, na mesma proporção, as personagens que formam a comitiva e que recusam a idéia de que uma mensagem tivesse sido enunciada por emissor tão pouco provável.

Quem ouve o recado é o Gorgulho, mas ele não esclarece como o morro pode se comunicar. Porém, quando a comitiva guiada por Pedro Orósio o enxerga à distância, ele parece escutar uma mensagem:

1. Indicaremos apenas as páginas de onde são retiradas as citações de "O Recado do Morro". 
E prestava atenção toda, de nariz alto, como se seu queixo fosse um aparelho de escuta. Ao tempo, enconchara mão à orelha esquerda (p. 624).

Logo, supõe-se que a comunicação seja lingüística, hipótese que se completa com a observação do narrador, para quem o morro apresenta-se "belo como uma palavra" (p. 626). Considerando a situação de transmissão da mensagem e a anotação do narrador, pode-se concluir que, nesse caso, predomine a linguagem verbal.

O ouvinte, porém, não estranha que o morro lhe mande mensagens; só não deseja envolver-se com o assunto, pois tem outro propósito em mente: deseja advertir o irmão que esse encontra-se em vias de casar com a pessoa errada. Por isso, não parece inclinado a colaborar, rejeitando as palavras que recebe e expressando suas reclamações de modo agressivo:

- Eu?! Não! Não comigo! Nenhum filho de nenhum... Não tou somando!

Tomou fôlego, deu um passo. Sem sossegar:

- Não me venha com loxias! Conselho que não entendo, não me praz: é agouro!

E mais gritava, batendo com o alecrim no chão:

- Oi, judengo! Tu, antão, vai p'r'as profundas!...

De tanta maneira, sincera era aquela fúria. Silenciou (p. 624).

A singularidade da situação não significa que seja inédita, sugerida, de certo modo, pelo vocativo "judengo", corruptela talvez de "judeu", empregado pelo Gorgulho, ao dirigir-se ao interlocutor. No Exxodo, segundo livro do Pentateuco, o hebreu Moisés apascenta o rebanho de Jetro, seu sogro, junto a "Horebe, o monte de Deus" (ÊXODO, p. 64), quando esse lhe aparece em meio a uma sarça ardente. Após apresentar-se ao futuro líder dos hebreus, ordena-lhe que livre seu povo do cativeiro:

Disse mais: Eu sou o Deus de teu pai, o Deus de Abraão, o Deus de Isaque, e o Deus de Jacó. Moisés escondeu o rosto, porque temeu olhar para Deus. Disse ainda o Senhor: Certamente vi a aflição do meu povo, que está no Egito, e ouvi o seu clamor por causa dos seus exatores. Conheço-lhe os sofrimentos, por isso desci a fim de livrá-lo da mão dos egípcios, e para fazê-lo subir daquela terra a uma terra boa e ampla, terra que mana leite e mel; o lugar do cananeu, do heteu, do amorreu, do ferezeu, do heveu e do jebuseu. Pois o clamor dos filhos de Israel chegou até mim, e também vejo a opressão com que os egípcios os estão oprimindo. 
Vem, agora, pois, e eu te enviarei a Faraó, para que tires do Egito o meu povo, os filhos de Israel, do Egito (ÊXODO, p. 64).

Tal como o Gorgulho, o pastor recusa a tarefa, não acreditando que será ouvido por seu povo ou pelo faraó, até ser convencido pelas demonstrações do poder divino. Essa não é, porém, a única oportunidade em que Deus se manifesta a Moisés no deserto, junto a um monte sagrado, pois é no alto do Sinai que são ditados a ele os mandamentos e as leis que doravante guiarão os judeus, até então escravos dos egípcios:

No terceiro mês da saída dos filhos de Israel da terra do Egito, no primeiro dia desse mês, vieram ao deserto de Sinai.

Tendo partido de Refidim, vieram ao deserto de Sinai, no qual se acamparam; ali, pois, se acampou Israel em frente do monte.

Subiu Moisés a Deus, e do monte o Senhor o chamou e lhe disse: Assim falarás à casa de Jacó, e anunciarás aos filhos de Israel:

Tendes visto o que fiz aos egípcios, como vos levei sobre asas de águias, e vos cheguei a mim.

Agora, pois, se diligentemente ouvirdes a minha voz, e guardardes a minha aliança, então sereis a minha propriedade peculiar dentre todos os povos: porque toda a terra é minha; vós me sereis reino de sacerdotes e nação santa. São estas as palavras que falarás aos filhos de Israel.

Veio Moisés. chamou os anciãos do povo, e expôs diante deles todas estas palavras, que o Senhor the havia ordenado (ÊXODO, p. 64).

Tal como o Horebe ou, sobretudo, o Sinai, o Morro da Garça é o lugar de uma epifania, o que posicionaria Malaquias no paradigma de Moisés. No caso da narrativa de Guimarães Rosa, porém, é o próprio acidente geográfico que se comunica com o Gorgulho, como se o monte substituísse a divindade, assimilando seus atributos.

A sacralização do Morro da Garça e a incorporação, pelo local geográfico, do papel desempenhado por Deus no Velho Testamento se fortalecem graças à caracterização de Malaquias, o primeiro dos sete recadeiros. Quando a comitiva o encontra, ele caminha pela mesma estrada reta seguida pelo grupo, sendo apresentado pelo narrador como "um homemzinho terémterém, ponderadinho no andar, todo arcaico" (p. 623). Orósio identifica-o como o Gorgulho, denominação que reforça seu aspecto antigo, observação intensificada pelo discurso indireto transcrito pelo narrador: 
Quem? Um velho grimo, esquisito, que morava sozinho dentro de uma lapa, entre barrancos e grotas - uma urubuquara - casa de urubus, uns lugares com pedreiras (p. 623).

Na seqüência, a descrição complementa a visão de um homem idoso, formal e trajado à moda antiga, anacrônico, mas não inverossímil ou insano:

Tinha um surrão a tiracolo, e se arrimava em bordão ou manguara. Como quase todo velho, andava com maior afastamento dos pés; mas sobranceava comedimento e estúrdia dignidade.

(...) Assim que, o Gorgulho calçava alpercatas, sua roupa era de sarja fusca, formato antigo - casacão comprido demais, com gualdrapas; uma borjaca que de certo tinha sido de dono outro - mas limpa, sem desalinho nenhum; via-se que ele fazia questão de andar composto, sem em ponto algum desleixar-se. E o que empunhava era uma bengala de alecrim, a madeira roxo-escura, quase preta (p. 623).

Na caracterização física e comportamental do Gorgulho, verificamse duas marcas importantes para a composição da personagem: ele reside nas profundezas da terra, razão provável de sua intimidade com o Morro da Garça ou, pelo menos, da possibilidade de ele ouvir e compreender o recado emitido pela natureza. Por sua vez, a descrição faculta a associação com os beatos que se espalharam pelo sertão brasileiro, dentre os quais o mais notório foi Antônio Conselheiro. Ao identificar o Gorgulho - "o nome dele, na verdade, era Malaquias" (p.623) - o narrador intensifica a associação entre o recadeiro e os "oráculos", papel que Machado de Assis numa de suas crônicas atribuiu ironicamente ao líder da revolta de Canudos (ASSIS, 1959, p. 276).

Malaquias constitui o último profeta, pois o livro que designa encerra o Velho Testamento. O livro que carrega seu nome, concluindo o tempo da profecia, anuncia a vinda do Senhor e o restabelecimento da justiça. Ele finaliza uma etapa, anunciando outra, por meio de uma interlocução sem contradição ou diálogo, razão pela qual se supõe que a palavra Malaquias, que intitula a obra, não se refira à pessoa do profeta, mas à função do "mensageiro".

Não apenas no Velho Testamento Malaquias é o nome que sinaliza o indivíduo capaz de profetizar. São Malaquias, figura do século XI, celebrizouse por ser capaz de anunciar eventos futuros, alguns tidos como comprovados. Ao se adonar do substantivo próprio para identificar a personagem, Guimarães 
Rosa reforça, pois, sua propensão profética. Distingue-o, assim, de Moisés, mas não desfaz sua capacidade de se comunicar com o divino e o sagrado.

Malaquias não transmite a mensagem apenas aos membros da comitiva guiada por Pedro Orósio. Quando o grupo encontra o irmão de Malaquias, Catraz, esse já conhece o conteúdo do recado, embora o diálogo entre os dois deva ter tido outro conteúdo, pois o Gorgulho desejava convencê-lo a não casar com uma moça que considerava inadequada.

Catraz é o apelido de Zaquias, esse sendo o nome do irmão de Malaquias. Substantivo próprio incomum, Zaquias não é indiferente ao universo religioso, já que uma personagem assim denominada aparece num dos evangelhos apócrifos, o do Pseudo-Mateus, na condição do mestre que deseja introduzir Jesus às leis da religião. O filho de José recusa os ensinamentos e, diante de Zaquias e de Levi, outro mestre a quem é conduzido o rapaz, mostra-se mais sábio do que os que desejam conduzi-lo à instrução.

No Evangelho do Pseudo-Mateus (http://www.supercable.es/ flor/apocri-25b.htm), Zaquias não é o homem da razão, nem está à altura de interagir com Jesus. Transportado para o universo da narrativa de Corpo de Baile, porém, faculta a introdução daquela personagem no contexto do relato, ampliando o paradigma religioso e mítico que embasa a viagem do recado original do morro. Conforme esse paradigma, o Morro da Garça corresponde aos espaços epifânicos - o Horebe e o Sinai - por onde passou Moisés, antes e depois de libertar os hebreus do jugo dos egípcios. Por sua vez, Malaquias e, em menor proporção, Zaquias reforçam sua condição, respectivamente, de profeta e mensageiro, capazes de transmitir a fala divina e anunciar o futuro, nem sempre auspicioso. Dois lugares ficam desocupados, se pensarmos na triangulação representada pelo Deus emissor / lugar sagrado / herói mítico: o da divindade, substituída pelo espaço, que, ao mesmo tempo, reforça sua sacralidade e desliga-se de Deus; e o do herói, Moisés, num caso, Jesus, em outro, ambos fundadores de nações, pois Malaquias, e depois Zaquias, conformam-se com a função de propagadores do recado.

Ao longo da trajetória da narrativa, o recado expande-se e esclarece-se, até chegar ao poeta e cantador Laudelim Pulgapé, autor dos versos que enuncia no baile. É então que se apresenta a conformação mais compreensível da mensagem, conforme um procedimento que valoriza simultaneamente a poesia, a criatividade do artista e a comunicabilidade da literatura. 
Quando Pedro Orósio ouve a canção de Laudelim, reproduzindoa enquanto se dirige para o encontro com Ivo Crônico, que planejara a tocaia vingadora e assassina, a mensagem alcança seu último e verdadeiro destinatário. De posse do conteúdo, Orósio descobre seu lugar no texto que migrava ao longo de sua caminhada, reaje e salva sua vida. A poesia, mostrandose clarividente, protege o protagonista e afiança seu futuro.

À primeira vista, o recado, que se desloca no espaço, parece se transformar do inarticulado para o articulado, ao passar da natureza emissora de modo cifrado para os versos cantados por Laudelim, como se a voz fosse a cadeia que garante a transmissão do conteúdo. Contudo, não é o lado fônico da mensagem que predomina: Pedro Orósio e seus companheiros de comitiva não ouvem a manifestação do morro, ao contrário de Malaquias, que responde ao emissor corporificado pela natureza. Malaquias, mensageiro desde o nome, não é, contudo, o homem da linguagem oral, e sim "garatujo" (p. 623), encarnando a escrita, com que se parece. Sob esse aspecto, "O Recado do Morro" concretiza uma teoria da linguagem, segundo a qual a escrita precede a oralidade, já que é Malaquias quem faz a migração do texto, de que é a representação material, para a palavra falada.

As relações do Morro da Graça com o mundo da escrita anunciam-se de maneira bastante particular. Ao descrevê-lo, o narrador o apresenta como "solitário, escaleno e escuro, feito uma pirâmide" (p. 624), provocando o olhar espantado e admirativo de Malaquias: "O Gorgulho mais olhava-o, de arrevirar bogalhos; parecia que aqueles olhos seus dele iam sair, se esticar para fora, com pedúnculos, como tentáculos" (p. 624).

A associação entre o morro e a pirâmide explica o caráter enigmático, e talvez mágico, do morro que manda recados. Por sua vez, a observação que o compara a um triângulo coloca-o em um universo que pode não ser racional, mas é o da civilização, porque lida com as abstrações e sínteses próprias ao mundo da escrita. Assim, o narrador pode afiançar, como citado antes, ser o Morro da Graça "belo como uma palavra” (p. 626). Senhor da linguagem, o monte que domina a região, porque "sempre dava ar de estar num mesmo lugar, sem se aluir, parecia que a viagem não progredia de render, a presença igual do Morro era o que mais cansava” (p. 632), coincide com o que exprime, numa fusão de significante e significado. Por essa razão, o sintagma que define sua beleza carece de verbo, mesmo o de ligação; o narrador precisa dar conta da imutabilidade e perenidade tanto do ente lingüístico, quanto do ser natural que lhe confere expressão. 
A fusão entre natureza e linguagem encontra sua manifestação mais completa no morro lingüístico, que fecunda uma narrativa e faculta a salvação de seu beneficiário, mesmo quando se trata do incrédulo Pedro Orósio. Mas ela é precedida pela frase que abre o relato.

"O Recado do Morro" começa com um prólogo do narrador, que explica o teor da história a ser contada:

Sem que bem se saiba, conseguiu-se rastrear pelo avesso um caso de vida e de morte, extraordinariamente comum, que se armou com o enxadeiro Pedro Orósio (também acudindo por Pedrão Chãbergo ou Pê-Boi, de alcunha), e teve aparente princípio e fim, num julho-agosto, nos fundos do município onde ele residia; em sua raia noroesteã, para dizer com rigor (p. 618).

A abertura retarda o início da narrativa, buscando estabelecer os parâmetros temporais e geográficos que alicerçam o relato, com o intuito de garantir a verossimilhança do que é contado. Ao mesmo tempo, ao confessar que o caso é "extraordinariamente comum", o narrador antecipa a desconfiança do leitor, estabelecendo de antemão a contradição entre o fantástico e o realismo de que se nutre a história. Essa, por sua vez, começa na oração seguinte: "Desde ali, o ocre da estrada, como de costume, é um S, que começa grande frase." (p.617)

Em um contexto em que a estrada é um $S$, inaugurando uma frase, logo, uma narrativa, o morro é a palavra que lhe confere expressão. Essa, por sua vez, está próxima da escrita, não apenas porque registrada por Alquist, seguidamente entendido como alter ego do autor, Guimarães Rosa. Mas sobretudo porque Malaquias, intérprete do morro e seu primeiro portavoz, a que se sucedem os demais (Catraz ou Zaquias, Joãozezim, Guégue, Nôminedomine, Coletor, Laudelim), parece, nas já citadas palavras do narrador, um "garatujo" (p. 623), isto é, corresponde ao rabisco que materializa a manifestação do Morro da Garça.

Malaquias, o mensageiro, é igualmente o "garatujo", gravando na escrita o texto que recebe do morro. O recadeiro coincide com a letra que dá origem à fala ou ao verbo; na seqüência do relato, a escrita converte-se na canção e, ao final, produz a ação, expressa pela reação de Pedro Orósio à ameaça de Ivo Crônico. Na obra de Guimarães Rosa, teses fundamentais da Lingüística - conforme as quais o significante é fônico e que o verbo nasce para dar expressão à ação dos homens - encontram-se invertidas. Dono, ele 
mesmo, enquanto escritor, do poder da palavra, reivindica a primazia para a arte que domina, colocando a si mesmo no começo da criação.

No versículo primeiro do Evangelho Segundo João, escreve-se que "No princípio era o Verbo, e o Verbo estava com Deus, e o Verbo era Deus" (EVANGELHO, 1967, p. 170). No texto de Guimarães Rosa, o Morro da Garça ocupa, desde o momento em que ele se comunica com o profético Malaquias e em que se reproduzem os diálogos de Moisés com a divindade, o papel de Deus. Mas o "Verbo" a que a narrativa se refere não tem expressão oral, e sim escrita, é redação, e não fala, como é próprio da Literatura, vocábulo que tem a letra na sua raiz. O escritor mineiro faz do relato a manifestação de sua visão da linguagem, porque talvez deseje também dar conta de uma teoria do Brasil.

\section{Uma alegoria do Brasil}

Ao lado da viagem do recado, tem-se a trajetória da comitiva guiada por Pedro Orósio e comandada por seu Alquist. O caminho percorrido pelo sertanejo pode ser entendido como a experiência, pelo herói, de um rito de passagem na direção de seu aperfeiçoamento.

As etapas do ritual estariam associadas às estações da comitiva, que cruza sete fazendas, cujos proprietários têm nomes associados aos astros do sistema solar. Elencam-se os nomes dos fazendeiros que acolhem os membros do grupo guiado por Orósio, bem como os astros que representam, relacionados em ordem de afastamento do Sol:

$\begin{array}{ll}\text { Lugares } & \text { Astros } \\ \text { Juca Saturnino } & \text { Saturno } \\ \text { Jove } & \text { Júpiter } \\ \text { Marciano } & \text { Marte } \\ \text { Nhá Selena } & \text { Lua } \\ \text { D. Vininha } & \text { Vênus } \\ \text { Nhô Hermes } & \text { Mercúrio } \\ \text { Apolinário } & \text { Sol }\end{array}$

A trajetória de Pedro Orósio comportaria componentes alquímicos, já que o herói se transferia do mundo sombrio, o do chumbo, de Saturno para o luminoso do Sol, da cor do ouro. Também a comitiva de Ivo 
Crônico, que acompanha Pedro Orósio e que pretende tocaiá-lo, é constituída por sete criaturas, equivalentes aos elementos celestes antes mencionados:

$\begin{array}{lll}\text { Lugares } & \text { Astros } & \text { Comitiva de Ivo } \\ \text { Juca Saturnino } & \text { Saturno } & \text { Ivo Crônico } \\ \text { Jove } & \text { Jupiter } & \text { Jovelino } \\ \text { Marciano } & \text { Marte } & \text { Martinho } \\ \text { Nhá Selena } & \text { Lua } & \text { João Lualino } \\ \text { D. Vininha } & \text { Vênus } & \text { Veneriano } \\ \text { Nhô Hermes } & \text { Mercúrio } & \text { Zé Azougue } \\ \text { Apolinário } & \text { Sol } & \text { Helio Dias Neme }\end{array}$

O paralelismo é construído com rigor, indicando a importância da passagem experimentada pelo herói, que primeiramente vivencia os espaços do ritual, e depois os derruba num gesto de magnitude mágica. É ao derrubar os inimigos que ameaçavam sua vida que Pedro Orósio comprova não apenas sua força física, mas igualmente sua aptidão para o papel central da narrativa. Ao fazê-lo, Pedro, enquanto personagens, transfere-se do âmbito fictício para o alegórico.

O protagonista da narrativa é caracterizado nos parágrafos iniciais, que, conforme referido antes, é o objeto do "caso de vida e de morte" relatado no texto. O narrador detém-se na aparência da personagem:

De guiador - a pé, descalço - Pedro Orósio: moço, a nuca bem feita, graúda membradura; e marcadamente erguido: nem lhe faltavam cinco centímetro para ter um talhe de gigante, capaz de cravar de engolpe em qualquer terreno uma acha de aroeira, de estalar a quatro em cruz os ossos da cabeça de um marruás, com um soco em sua cabeloura, e de levantar do chão um jumento arreado, carregando-o nos braços por meio quilômetro, esquivando-se de seus coices e mordidas, e sem nem por isso afrouxar o fôlego de ar que Deus empresta a todos (p. 617).

2. Saturno é, na mitologia grega, Cronos, o tempo.

3. Conforme Ana Maria Machado, "Zé Azougue (...) é Mercúrio na linguagem popular brasileira" (MACHADO, 2003, p. 112). 
A força física de Pedro é assombrosa, assemelhando-o a um gigante, nas palavras do narrador, revivendo o bíblico Sansão, conforme a percepção de Alquist. ${ }^{4}$ Perto do final do relato, diz dele o narrador:

Deveras, tinham receio. Pois não era? Um exagero de homem-boi, um homão desses, tão alto que um morro, a sobre. Assim desmarcado, pescoço que não dobrava, braços de tamanduá, inchos de músculos, aquilo era de ferro se ele estouvava, perigava qualquer sociedade, destruía as certezas (p. 664).

Ele é também o homem da terra, relacionamento que se expressa pela dificuldade de o protagonista calçar sapatos ou botinas, como é indicado no começo da narrativa e reforçado ao final, quando "Pedro Orósio esbarrou. As botinas o maltratavam. Sentou no chão, se livrou. Deu ao Ivo as botinas, para levar" (p. 665).

A caracterização de Pedro reproduz, pois, emblemas com que se representa o Brasil: tanto o gigantismo geográfico, quanto a a associação com a natureza, que os versos de Joaquim Osório Duque Estrada traduzem no hino nacional. A conhecida estrofe que fala do "Gigante pela própria natureza, / És belo, és forte, impávido colosso" pode ser lida como uma descrição aplicável sob medida ao protagonista de "O Recado do Morro".

Por sua vez, o moço está ameaçado de morte por emboscada, resultante do engano a que o conduzem os companheiros de Ivo Crônico. Na configuração do perigo, que Pedro só percebe nas derradeiras cenas da narrativa, reconhece-se um elemento mítico: a traição de que é vítima Jesus Cristo por efeito da ação de Judas, o apóstolo desleal. Se o filho de José e Maria estava indiretamente implicado em "O Recado do Morro" em conseqüência da alusão ao recadeiro Zaquias, agora ele se mostra inteiramente na qualidade de paradigma que inspira a criação de Pedro Orósio.

O rapaz, porém, suplanta o risco, graças ao aviso do Morro da Garça, cuja mensagem o alcança de várias maneiras, desde a enigmática expressão do profético Malaquias até sua tradução em rimas por Laudelim. A natureza, de que ele representa o prolongamento, por seu gigantismo e afinidade, envia o recado primeiro que propicia a remissão do herói. Também por esse caminho retomam-se mitos de representação da brasilidade, conforme

4. Cf. MACHADO, 2003, p. 117. 
os quais o país é sintetizado por uma natureza pujante, cuja riqueza e fecundidade garantem a felicidade dos homens. Pedro é, simultaneamente, essa terra e esse homem, porque se comunica com a natureza e é capaz de extrair de sua potência física a solução para seus problemas.

Tal como Jesus, entidade que preside um dos paradigmas sobre os quais se constrói a personagem, Pedro está ameaçado de morte por traição. Ressalte-se que o malefício não provém dos membros da comitiva que está encarregado de guiar. O grupo formado de letrados, como Alquist e Sinfrão, não constitui perigo, ainda que os dois, o cientista e o religioso, pudessem corporificar o estrangeiro que ocupa a terra, extraindo suas riquezas ou desejando dominar sua alma. A eles interessa, porém, o conhecimento científico do espaço, não o proveito econômico ou espiritual. Por outro lado, Sinfrão e Alquist não estão preparados para entender os sinais da natureza: reificando-a em decorrência do tipo de pesquisa que desenvolvem, pois a entendem enquanto objeto de análise, não percebem que o espaço constitui um sujeito que se manifesta por meio de uma linguagem, cifrada mas, ao mesmo tempo, codificada na escrita.

Por causa desse equívoco, minimizam o conteúdo da mensagem enunciada por Malaquias, de que é exemplo a manifestação de frei Sinfrão:

- "Possível ter havido alguma coisa?" - frei Sinfrão perguntava. - "Essas serras gemem, roncam, às vezes, com retumbo de longe trovão, o chão treme, se sacode. Serão descarregamentos subterrâneos, o desabar profundo de camadas calcáreas, como nos terremotos de Bom-Sucesso... Dizem que isso acontece mais é por volta da lua-cheia..."

Mas, não, ali ilapso nenhum não ocorrera, os morros continuavam tranqüilos, que é a maneira de como entre si eles conversam, se conversa alguma se transmitem. O Gorgulho padeceria de qualquer alucinação; ele que até era meio surdo (p. 624).

Alquist, por seu turno, identifica no poema de Laudelim as correlações épicas que fariam de Pedro Orósio o herói do texto; mas não

5. Ana Maria Machado lembra que a relação dos astros por onde transita Pedro exclui o planeta Terra, pois esse estaria representado pelo protagonista da narrativa: "Porque ele é também a Terra, planeta ao qual todos os outros astros do sistema se estão opondo: o sol, a lua, Mercúrio, Vênus, Marte, Júpiter e Saturno" (MACHADO, 2003, p. 117). 
ultrapassa a medida de sua formação européia, aproximando os versos ao modelo medieval da literatura, e não à situação que eles mesmo testemunham:

Tarefa que se levava, pois o senhor Alquist queria comentar muito, em inglês ou em francês, ou mesmo em seus cacos de português, quando não se ajudando com termos em grego ou latim. - "Digno! Digno! Como na saga de Hrold filho de Helgi, Hrolf o Liberal: ainda era menino, quando Helgi morreu, e ele subiu ao trono da Dinamarca..." Referia: - "Ah, está em Saxo Grammaticus! Ou quando o outro, Hrolf Kraki, entrou na peleja: foi como um rio estua no mar - ele simultâneo, a todo átimo pronto na espada, qual com os bífidos cascos o veado se atira... Está em Saxo Grammaticus..." (p. 662)

Se os estrangeiros não adotam posicionamento colonialista, por outro lado, mostram-se incapazes de compreender o que se passa a seu redor, deixando Pedro entregue à própria sorte e, sobretudo, aos meios de que dispõe para superar a dificuldade a que fora jogado e que precisa decodificar para reagir convenientemente.

Tal como Jesus, Pedro é traído por seus companheiros, o saturnino Ivo Crônico, indivíduo de amores frustrados que, no andar da comitiva, ocupa o último lugar. Contudo, Pedro não é vencido por Crônico e seus asseclas, nem é obrigado a qualquer sacrifício. Pelo contrário, derruba os inimigos e, vitorioso, desloca-se na direção dos Gerais, sinônimo de seus sonhos de vida independente e bem sucedida. Nos últimos parágrafos da narrativa, quando se anunciava o infortúnio, dá-se a reversão das expectativas, graças à correta intepretação da mensagem iniciada pela profecia de Malaquias.

Ao entender o recado do morro, Pedro integra-se a novo paradigma - o de Moisés, já mencionado, configurando sua imagem de fundador e líder de um povo que se dirige à Terra Prometida, os Gerais na interpretação do protagonista do texto. Não por outra razão ele chama-se Pedro, nome duplamente motivado, pois designa tanto o apóstolo a quem Jesus confiou a difusão de suas idéias e que deu início a uma religião, quanto o indivíduo histórico que libertou o Brasil do jugo português, o monarca que rompeu com sua pátria de nascença para inaugurar uma nação na terra que o adotou.

Pedro é nome de herói fundador, designando um Moisés para o Brasil nascente, cuja autenticidade situa-se não na cidade, que Orósio rejeita, mas nas áreas mais ocidentais do território, para onde aponta seu futuro. Em "O Recado do Morro", uma outra carta do achamento é redigida, e é esse novo Pedro, substituindo o velho Pero Vaz, que encontra na escrita as vias a percorrer. 
Disponivel em: http://www.letras.ufmg.br/poslit

Abstract: "O Recado do Morro", one of the narratives from Corpo de Baile (1956), published by Guimarães Rosa, rest on the motive of the travel to asseverate the superiority of writing and to express a allegory of Brazil.

Key words: writing; allegory; travel; prophecy; language.

\section{Referências Bibliográficas}

ASSIS, Machado de. A Semana. São Paulo: Mérito, 1959. V. 4.

Evangelho Segundo São João. In: O Novo Testamento. Trad. João Ferreira de Almeida. São Paulo: Cia. Publicadora Nacional, 1967.

"Êxodo". Bíblia. Versão portuguesa de João Ferreira de Almeida. S. 1., s. e., s. d.

http://www.supercable.es/ flor/apocri-25b.htm. Consultado em 21 de maio de 2006.

MACHADO, Ana Maria. Recado do Nome. 3. ed. Rio de Janeiro: Nova Fronteira, 2003.

ROSA, João Guimarães. O Recado do Morro. In: . Ficção Completa. Rio de Janeiro: Nova Aguilar, 1995. V. 1. 